\title{
El budismo en el discurso político chino: construcción de una narración patriótico-religiosa
}

\author{
Buddhism in Chinese Political \\ Discourse: Construction \\ of a Religious-patriotic Narrative
}

\section{MARÍA ELVIRA RÍOS PEÑAFIEL*}

Resumen: Tres son las grandes persecuciones que el budismo debió enfrentar y superar en la historia de China, y variadas las maneras en que ha debido crear un discurso que se adecue a las circunstancias culturales y políticas para sostener su doctrina. A principios del siglo xx enfatizó un discurso modernizador, para luego adaptar los conceptos religiosos a la ideología comunista. En la actualidad, el budismo debe responder a la política patriótica del "sueño chino". En este texto se analiza la narración político-religiosa por medio del uso de conceptos e ideas que circulan en los medios de comunicación y en conferencias que la Asociación Budista de China difunde entre el pueblo creyente.

Palabras clave: budismo; China; religiones; políticas chinas; partidos.

Abstract: On three occasions Buddhism had to face and overcome major persecutions in the history of China, and there were various ways by which it created a discourse adapting to cultural and political circumstances in support of its doctrine. In the early twentieth century Chinese Buddhism emphasized a modernizing discourse, in order to later adapt its religious concepts to communist ideology.

Recepción: 22 de junio de 2016. / Aceptación: 23 de agosto de 2016.

* Universidad del Desarrollo, mrios@colmex.mx 
Today, Buddhism must respond to the Xi Jinping patriotic policy of the "Chinese Dream". This paper aims to analyze the religious-political narrative through the use of concepts and ideas circulating in the media and public talks that the Buddhist Association of China promotes among believers.

Key words: Chinese Buddhism; political discourse; Chinese religion; Chinese government; Chinese society.

Quien se adentre en el contenido de la página electrónica de la Asociación Budista de China, Zhōngguó Fójiào Xiéhui 中国佛 教协会, ${ }^{1}$ observará que, en el apartado de “Introducción”, se describen las responsabilidades que esta asociación tiene para y con la sociedad. La lista comienza con la unificación: guiar a cada uno de los devotos budistas de distintas nacionalidades chinas a un sentimiento de "amor a la patria y a la doctrina" ( $\grave{A}_{i}$ guó ài jiāo 爱国爱教); colaborar con el presidente del Partido Comunista Chino y el sistema socialista, "inquebrantables [jiāndingbùyí 坚定不移] en el distinguido camino socialista”; respetar la Constitución, las políticas y las leyes del país; colaborar con el gobierno en la implementación de las políticas de libertad religiosa y en las regulaciones de las leyes, defendiendo los derechos legales y los intereses del mundo budista; profundizar en la investigación del budismo, dar a conocer el organismo budista, la opinión y las solicitudes de los budistas; estrechar las relaciones entre los discípulos budistas de todas las nacionalidades; promover el intercambio de los tres idiomas (chino, tibetano, pali) en el budismo y la unión de las nacionalidades; aumentar la devoción hacia la religión; administrar de buena manera las instituciones y los colegios budistas; formar personas budistas talentosas; promover las investigaciones y las actividades budistas, así como realizar obras caritativas. Posteriormente, señala la promoción amistosa de las relaciones con los compatriotas (tóngbāo 同胞) de Taiwan, Hong Kong, Macao y los residentes budistas chinos en el extranjero, así como la comprensión y la cooperación para promover la unión con la Madre Patria (zǔguó 祖国). Además, la asociación debe au-

${ }^{1}$ Los términos en chino se escribieron utilizando el sistema de transcripción fonética pinyin. Los caracteres chinos se agregaron en la primera mención del término. 
mentar la cohesión cultural entre las nacionalidades chinas y desarrollar la amistad y la interacción con organizaciones budistas internacionales, con otras religiones y con cada país budista. Finalmente, tiene que promover el intercambio cultural entre los budistas chinos y los budistas extranjeros, para mantener la paz en el mundo. ${ }^{2}$

En este breve pero intenso párrafo de introducción se observa que la tarea de la asociación no es menor, pues su primera obligación tiene que ver con la colaboración para la unificación social que lleve a un compromiso con el país y, por lo tanto, con el partido. Estas tareas combinan labores que son parte de las responsabilidades religiosas que el budismo promueve, pero otras apuntan explícitamente a las políticas internas del partido. Las asociaciones de las cinco religiones oficiales de China (budismo, daoísmo, islam, protestantismo y catolicismo) cumplen un papel crucial en el vínculo entre el Estado y el pueblo. Las asociaciones reciben la protección y los beneficios del gobierno, siempre y cuando se atengan a las regulaciones del partido. Entre las asociaciones religiosas, la budista es, sin lugar a dudas, la más influyente en la sociedad china.

En este discurso introductorio de la Asociación Budista, hallamos conceptos que se repiten de manera constante en los textos y las noticias que publica en su página electrónica, los que representan el lema "Amor a la patria y a la doctrina" (desde ahora, Ài guó ài jiāo). Este lema nació en la década de 1990 y su origen se debe a la búsqueda de una teoría adecuada a las políticas socialistas del Estado para que las religiones también participen. A su vez, responde a otra de las tantas maneras en que las religiones han buscado acomodarse a las circunstancias históricas y políticas del país. En este texto analizo la narrativa político-religiosa de la Asociación Budista de China, destacando los procesos de inserción de lo político en la doctrina, con la intención de reflexionar sobre los factores teóricos y situacionales que han construido los discursos y las frases emblemáticas de la asociación religiosa más influyente en China. Con factores teóricos y situacionales me refiero a la fundamentación teórica

${ }^{2}$ Asociación Budista de China, "Breve introducción a la Asociación Budista de China” (中国佛教协会简介 Zhōngguó Fójiào xiébuì jiăn jiè), abril de 2012. 
de la reinterpretación de la doctrina budista desde principios de siglo Xx hasta el presente, para adecuarse a la realidad política y a las necesidades del Partido Comunista. Al conocer esos factores, es posible analizar el discurso actual del budismo chino y los elementos que influyen en su construcción. Al respecto, surgen las siguientes preguntas: ¿hay una reinterpretación de la doctrina para adecuarla a las necesidades actuales del gobierno chino?, ¿cómo influye el contexto social, moderno y global de la actualidad?, ¿qué ideas o conceptos se incorporan al discurso?, ¿cómo se aplica el discurso político-religioso en la sociedad?

Con base en lo anterior, sugiero que tanto el discurso budista que se adapta a la estrategia del partido como la influencia de los neobudismos estadounidense y europeo coexisten y construyen un diálogo que responde a las necesidades sociales sin desvincularse de las políticas gubernamentales. A lo anterior se suma el discurso budista asiático moderno que se manifiesta en el budismo humanista de la corriente Foguangshan, en Taiwan. La Asociación Budista incorpora y adapta algunas características modernizadoras del Foguangshan que acercan el budismo de la isla al del continente. La unión de estos tres elementos da origen a un discurso religioso patriótico y moderno. Para referirnos a ellos es preciso señalar los antecedentes históricos del discurso político-religioso que nos permitirán analizar con mayor precisión y conocimiento la construcción del discurso actual.

\section{Antecedentes históricos}

Los intentos de sobrevivencia de los religiosos ante las circunstancias políticas del momento son parte de la historia de las religiones. El budismo en China tuvo que superar periodos trágicos en que los poderes imperiales reprimían la religión. Durante la República (1912-1949), la búsqueda de la modernización significó el inicio de la secularización. Francesca Tarocco señala que las nuevas élites que suplantaron el antiguo orden confuciano tenían un sentimiento anticlerical. Las propiedades monásticas budistas fueron amenazadas y se atacó a los monjes en las campañas antirreligiosas que surgieron en 1920. De ese 
periodo destacan las reformas del maestro Taixu (1889-1947), quien defendió el budismo, promovió la educación e impulsó la creación de las escuelas con recursos de los templos, la libertad de practicar la religión y la protección de todos los templos. ${ }^{3}$ Los religiosos siguieron el modelo cristiano de obras caritativas, como la creación de orfanatos y escuelas. ${ }^{4}$

Tras el triunfo de Mao Zedong, el Partido Comunista ubicó el budismo como una doctrina cuya filosofía apoyaba el pensamiento imperialista, daba prioridad a las clases sociales elitistas y contribuía a la división de clases, con lo que acentuaba las diferencias en la sociedad. ${ }^{5}$ Frente a la difícil situación política, los monjes buscaron compatibilizar el budismo con el comunismo. Su estrategia general fue la de identificar ciertas ideas o prácticas budistas y reinterpretarlas en términos marxistas-socialistas. Algunas ideas se leían en la publicación periódica de la sangha, en la revista Modern Buddhism. Entre las publicaciones se encuentra una conferencia del presidente de la Asociación Budista de China donde señala que hay diferencias entre política y religión que se pueden resolver de la siguiente manera: "si hay ciertas diferencias que violan las políticas del partido, entonces el budismo debe ponerse del lado del partido más que del de la religión; debe dejar los puntos de vista budistas y obedecer absolutamente las políticas del partido". 6

David Yu señala que entre estas adecuaciones doctrinarias que debía realizar el budismo chino está la de la cadena del ciclo

\footnotetext{
${ }^{3}$ Francesca Tarocco, The Cultural Practices of Modern Chinese Buddhism. Attuning the Dharma, Nueva York, Routledge, 2007, p. 34.

${ }^{4}$ En el intento de mayor colaboración con la sociedad, realizaron acciones similares a las que llevaban a cabo los cristianos. Una de ellas fue durante la hambruna de 1921, cuando se estableció una asociación budista para enviar víveres y vestimentas a las provincias del norte. Véase Holmes Welch, The Practices of Chinese Buddhism 19001950, Cambridge, Harvard University Press, 1967, p. 377. En Beijing, los monjes del monasterio Guanji eran oficialmente invitados para actuar como instructores morales. También se establecen imprentas para las publicaciones de revistas budistas y colegios monásticos. Véase Stuart Chandler, Establishing a Pure Land on Earth. The Foguang Buddhist Perspective on Modernization and Globalization, Honolulu, University of Hawai'i Press, 2004, p. 182. Los monjes solían visitar las cárceles que se ubicaban en la isla Putuoshan, en Wuxi y Shanghái, y enseñaban a los presos la lectura de sūtras, la recitación de los textos e incluso les permitían utilizar los instrumentos litúrgicos. Véase Tarocco, The Cultural Practices..., op. cit., p. 26.

${ }^{5}$ David C. Yu, "Buddhism in Communist China: Demise or Co-Existence?", Journal of the American Academy of Religion, vol. 39, núm. 1, marzo de 1971, pp. 51-52.

${ }^{6}$ Ibid., pp. 52-53.
} 
de nacimiento y muerte de los seres vivos, el cual se debe al karma negativo del pasado, que tiene su origen en los tres venenos: gula, ira e ignorancia. El budismo de ese entonces interpretaba esos venenos en términos socialistas: "son los pecados de una sociedad capitalista, el resultado de las prácticas de propietarios privados. En una sociedad colectivista, la causa de estos venenos debe ser eliminada". De esta manera, las autoridades religiosas de la asociación reinterpretaron el sentido de liberación de los ciclos de renacimiento y, por lo tanto, de la provocación del sufrimiento, como una liberación de la sociedad capitalista. ${ }^{7}$

Otra de las audaces reformulaciones de la doctrina se refiere al deseado paraíso budista de la Tierra Pura del Buda Amitābha. El maestro Taixu ya había anunciado la idea de concebir esta tierra como el paraíso, es decir, hacer de nuestro mundo la Tierra Pura. Pero los religiosos de la Asociación Budista añadieron que el paraíso podía identificarse con este planeta, siempre y cuando fuera un mundo con una sociedad marxista. Para que eso fuera posible, las personas debían purificar sus mentes, lo que se traducía como una renovación, un cambio completo de pensamiento. ${ }^{8}$

A pesar de los intentos, las religiones fueron poco a poco reprimidas, y en la Revolución Cultural (1966-1976) se prohibieron las prácticas religiosas, se destruyeron los templos y se obligó a miles de monjas y monjes a abandonar la vida religiosa. En ese entonces se creía que China prontamente se convertiría en un modelo de sociedad posrreligiosa, secularizada. ${ }^{9}$

A finales de la década de 1970, y con la muerte de Mao Zedong, el partido debía superar el gran desastre de la Revolución Cultural. En ese entonces, Zhao Puchu (más conocido como Zhao Pulao) era el presidente de la Asociación Budista de China. Su teoría de adaptación de las religiones al gobierno chino dio origen al actual lema "À i guó ài jiäo". Zhao sabía que las religiones debían recuperarse, siempre y cuando sus creyentes trabajaran para adaptarse al partido. Para eso tuvo que buscar la manera de responder a preguntas como: ¿qué es la reli-

${ }^{7}$ Ibid., p. 53.

${ }^{8}$ Idem.

9 Rodney Stark y Eric Y. Liu, “The Religious Awakening in China”, Review of Religious Research, vol. 52, núm. 3, marzo de 2011, pp. 282-289. 
gión?, ¿cuáles son las condiciones para que una religión exista o desaparezca?, ¿cómo debemos entender el concepto de "ateísmo" (wúshénlùn 无神论)?, ¿cuál es la manera correcta de comprender la idea marxista sobre la religión como el opio de los pueblos? ${ }^{10}$

Zhao Pulao señala que fue un error la manera en que Lin Biao y la Banda de los Cuatro ${ }^{11}$ advirtieron sobre el culto a la personalidad en las religiones. Ellos, afirma Zhao, se aprovecharon de los cuadros del partido, de la gente trabajadora, del carisma y el respeto de los líderes que les entregaban los miembros del partido para tratar de resolver de manera apresurada el culto a la personalidad, que surge tanto de un pensamiento idealista como del feudalismo. Agrega que el pueblo se dio cuenta de que la manera en que procedieron Lin Biao y la Banda de los Cuatro, al usurpar el poder del partido, reprimir al pueblo, empobrecer la economía y desplomar la cultura, no se relacionaba con las creencias de las personas religiosas. Zhao afirma que esta idea de considerar el culto a la personalidad como una "nueva religión" es una falta de criterio y de argumento teórico, y se pregunta: “¿Acaso esta 'nueva religión' tiene principios que la protejan? Claramente es muy absurdo". De ahí que declare que esta forma no científica de criticar la teología religiosa, de difundir el ateísmo, de eliminar a los creyentes religiosos, fue un método de Lin Biao y la Banda de los Cuatro que dañó a la nación. ${ }^{12}$

Luego, Zhao Pulao señala que para lograr una unificación en paz, para que se lleven a cabo las cuatro modernizaciones (agricultura, ciencia, tecnología industrial y defensa nacional), se debe avanzar en la política de libertad de creencias y no provocar disputas en torno a la religión. En cuanto al ateísmo, afir-

${ }^{10}$ Zhang Qi, "Las múltiples contribuciones del devoto laico Zhao Puchu en las decisiones sobre la política, leyes, teoría y práctica de las religiones en nuestro país en este nuevo periodo" (赵朴初居士对新时期我国宗教政策、法律、理论、实践方面 做出的诸多贡献, Zháo Pǔzhū jūshì duì xinn shíqi wǒguó zōngiiào zhèngcè, fălù, lìlùn, shíjiàn fängmiàn zuòchū de zhūduō gòngxiàn), Fojiao Yanjiu 佛学研究, vol. 1, 2014, p. 391.

${ }^{11}$ El general y ministro de Defensa de Mao Zedong, Lin Biao y la Banda de los Cuatro (Jiang Qing, Zhang Chunqiao, Yao Wenyuan y Wang Hongwen) fueron quienes promovieron la Revolución Cultural (1966-1976) y permitieron la violencia extrema de los guardias rojos.

${ }^{12}$ Ibid., p. 392. 
ma que entre los principios del marxismo se encuentra el ateísmo, y recalca una frase de Lenin en El discurso sobre la actitud del Partido del Trabajador hacia la religión, donde el líder marxista destaca que el ateísmo es un compromiso fundamental de obediencia al partido. Zhao interpreta esta frase como la unión de las masas y las religiones hacia un camino de socialismo moderno, civilizado y democrático. ${ }^{13}$ De esta manera, no se trataría de eliminar las religiones, sino de unirlas a las políticas socialistas del partido, percepción que es, sin lugar a dudas, una de las bases del pensamiento actual sobre las prácticas religiosas en China.

Respecto a la consideración de Marx de que la religión es el opio del pueblo, Zhao argumenta que no se trata de que el pensamiento marxista culpe a las personas de "drogarse" con la religión y tampoco de que sus religiones sean las que exploten a las clases, sino que es una manera de protestar contra quienes explotaron al pueblo por medio de la religión. Junto con el argumento sobre el ateísmo que señala Zhao, esta interpretación representa uno de los mejores y más exitosos ejemplos de construcción de una narrativa sociorreligiosa que logra adecuarse a las políticas del Estado, reconciliarse con el partido y así proteger la institución religiosa.

Zhao Pulao continúa exponiendo su teoría con otro ejemplo: un documento de Li Wei Han (1896-1984), director del Frente Unido del Partido Comunista en 1948. En el documento, Li Wei Han presenta cinco naturalezas o características de la religión en China: la religión de masas, el aspecto nacional, el aspecto internacional, la complejidad de la religión y su extensión. Zhao comparte estas características y las interpreta diciendo que si la religión de masas “completa su trabajo" (zuò hăo zōngïào gōngzuò 做好宗教工作), puede influir en cientos de millones de personas para que se lleven a cabo la reforma y la apertura al mundo, la paz en la sociedad y la unificación con la madre patria. Sobre el aspecto nacional, recalca que China tiene muchas minorías étnicas con distintas religiones, la mayoría de las cuales se ubica en los lugares más apartados y limítrofes del país. Por lo tanto, "si las religiones completan su 
trabajo" - repite la frase-, pueden colaborar a la unidad entre minorías y consolidar la defensa de las fronteras. Respecto al carácter internacional, al existir tantas religiones en el mundo, donde muchas ejercen como la doctrina dominante de los países, podemos ver que "si las religiones completan su trabajo", adquieren importancia en lo que se refiere a la protección y la paz mundial. Sobre la complejidad de la religión, Zhao señala que, aparte de su carácter masivo, nacional e internacional, las religiones tienen otros elementos complejos, como la variedad de sectas, doctrinas, teorías, reglas monásticas, en fin, pensamientos religiosos muy ricos y diversos que permiten un vínculo más íntimo y cercano con la gente. Por esto se deben entender las religiones desde sus aspectos más complejos para tratar con ellas. Finalmente, sobre la extensión de las religiones, señala que éstas, al igual que las sociedades, surgen, se desarrollan y pueden desaparecer. Pero si tanto las religiones como las sociedades se mantienen en el tiempo, no desaparecerán.

Con base en la adecuación del budismo a las políticas socialistas que realiza Zhao Pulao, en el informe del Comité Central del Partido Comunista sobre el reforzamiento del trabajo del Frente Unido de 1990 se hizo un llamado a guiar las religiones patrióticas y a las personas para que integraran el amor a la doctrina y al país, y llevaran las actividades religiosas a los parámetros de la Ley y la Constitución y las adaptaran al sistema socialista. ${ }^{14}$

La consideración de las religiones en las políticas de China acontece en un periodo en el que se apuesta por un nacionalismo que incluye las tradiciones culturales, donde destacan los valores confucianos como fuentes culturales del crecimiento político y económico de China. Desde esta perspectiva, se sugiere que el desarrollo del actual nacionalismo chino también puede ser comprendido desde lo que se conoce como estrategias narrativas para los actores políticos. Falk Hartig las describe desde el ámbito de la política internacional de China; sin embargo, también pueden ser descritas desde el ámbito social local. Hartig señala que son narrativas de los Estados y los sistemas 
en sí mismos, cuyo objetivo es influir en el comportamiento de los otros. ${ }^{15}$

En el contexto histórico y narrativo descrito, la administración religiosa adquiere una institucionalidad nacional; en 1998, la que funcionaba como Oficina de Asuntos Religiosos del Consejo de Estado (Guóyùyuàn Zōngjiào Shìwùjú 国务 院宗教事务局) se estableció como la Oficina Nacional de Asuntos Religiosos (Guójiā Zōngjiào Shìùjjú 国家宗教事务 局). ${ }^{16}$ Entre sus responsabilidades se señala:

Guiar a las organizaciones religiosas de acuerdo con las leyes y las regulaciones del desarrollo de actividades, mantener a las organizaciones religiosas fortaleciendo sus propias estructuras, ayudar a las organizaciones religiosas en la administración de sus monasterios y establecimientos educacionales, promover que en los círculos religiosos las organizaciones desarrollen el patriotismo, el socialismo, el apoyo a la madre patria, la unificación de las nacionalidades y la autoeducación de la unidad de los grupos étnicos, y conducir los asuntos de las organizaciones religiosas mediante la coordinación o resolución del gobierno. ${ }^{17}$

\section{El discurso budista chino del siglo XXI}

El lema "À i guó ài jiāo" ha sido fundamental en el discurso del presidente Xi Jinping sobre la política del "sueño chino", donde converge con los ideales de una sociedad armónica, civilizada y patriótica del partido. ${ }^{18}$ A su vez, la Asociación Budista incorpora otras frases que pretenden transmitir los mismos valores. Entre ellas destaca: Zhuāngyánguótǔ lilèyǒuqíng 庄严国 土, 利乐有情, “Dignificar al país y dotar [a las personas] de sen-

${ }^{15}$ Alister Miskimmon, Ben O’Loughlin y Laura Roselle, Strategic Narratives: Communication Power and the New World Order, Nueva York, Routledge, 2013, p. 2.

${ }^{16}$ Oficina Nacional de Asuntos Religiosos, "Cambio y desarrollo histórico" (历 史沿革 Lish ȟ yánggé), 27 de mayo de 2015.

${ }^{17}$ Idem.

${ }^{18}$ El sueño chino de Xi Jinping insiste en la particularidad de un socialismo con peculiaridades chinas. Esta característica se representa por medio de ideas como un mundo armonioso (vinculado a la filosofía confuciana y daoísta), civilizado (uno de los conceptos al que el gobierno chino acude constantemente en sus discursos sobre comportamiento social) y patriótico (amor a la patria, por lo tanto, al partido). La suma de estos conceptos llama a una revitalización del país, idea que engloba la teoría de sueño chino de Xi Jinping. 
timiento de alegría y beneficios”. El primer registro que se tiene de este lema es en un discurso de Zhao Pulao durante su cargo como presidente de la asociación en 1987. Surgió en el Quinto Encuentro Nacional de Asociaciones Budistas, que Zhao Pulao tituló: "Levantémonos unidos, desarrollemos la excelente tradición budista para contribuir a dignificar al país y dotar [a las personas] de sentimiento de alegría y beneficios" ${ }^{19}$ En el texto, Zhao destaca los avances de la asociación en los seis años anteriores (desde el Cuarto Encuentro Nacional de Asociaciones Budistas en 1980) para colaborar con el partido a “traer el orden en el caos” (bōluànfänzbèng 拨乱反正), con lo que hace referencia a las dificultades sociales y económicas que vivió el país en el periodo previo a la reforma de 1978, en colaboración con las políticas socialistas del gobierno. Al respecto, Zhao Pulao alude a una "nueva historia del budismo en China":

De esta manera es como el budismo chino comienza a avanzar en un camino coordinado con el socialismo característico de China. Debemos seguir esforzándonos persistentemente, con armonía y unidad, llevando a cabo la administración educacional, desarrollando la excelente tradición budista, para dignificar al país y dotar [a las personas] de alegría y beneficios, para unir a la madre patria, revitalizar China, progresar sin descanso en la paz mundial y lograr una nueva contribución. ${ }^{20}$

Más adelante, Zhao Pulao menciona la promoción de la unidad de la madre patria y la protección de la paz mundial:

Reunificar y revitalizar a la madre patria ha sido el propósito de lucha común de todos los descendientes de Yan Di y Huang Di $;{ }^{21}$ nuestros discípulos budistas deben contribuir a alcanzar este objetivo. El budismo

${ }^{19}$ Asociación Budista de China, "Unámonos, contribuyamos al desarrollo de la buena tradición budista para dignificar al país y dotar [a las personas] de alegría y beneficios” (团结起来, 发扬佛教优良传统为庄严国土利乐有情作贡献 - 在中 国佛教协会第五届全国 Tuánjié qǔlai fayáng fójiào yōuliáng chuántǒng wèi zhuāngyán guótǔ lìlè yǒnqíng zuò gòngxiàn - zài Zhōngguó Fójiào xiébuì dì wǔ jiì quánguǒ), 23 de febrero de 1987.

${ }^{20}$ Idem.

${ }^{21}$ La frase "descendientes de Yan Di y Huang Di" es una de las maneras en que los chinos se llaman a sí mismos. Según la leyenda, Yan Di (o Shennong, Emperador de los cultivos y la medicina) y Huang Di (Emperador Amarillo) habrían sido los primeros emperadores, los cuales dieron origen al pueblo buaren, los chinos. 
posee una extensa y profunda influencia en los compatriotas de Hong Kong, Macao y Taiwan, en los chinos residentes en el extranjero, así como en los ciudadanos extranjeros de origen chino. Muchos de los chinos que habitan en el extranjero consideran fundamental el budismo del continente y lo estiman con un sentimiento profundo. La gran tarea de nuestro budismo es facilitar el campo de visión: con los pies en el país mirar hacia el exterior, reforzar las relaciones de amistad y las comunicaciones, hacer amigos, lograr que todos los discípulos budistas en el país o en el extranjero, en conjunto, desarrollen la doctrina budista, dignifiquen al pais y doten [a las personas] de alegría y beneficios, impulsar la implementación de "un país y dos sistemas", promover la unidad pacífica de la madre patria y revitalizar China; ésta es la más importante responsabilidad a largo plazo del trabajo del budismo.22

\section{En los registros que guarda la Oficina Nacional de Asuntos} Religiosos en su página electrónica se aprecia que el lema de Zhao Pulao fue utilizado en los primeros años del periodo del expresidente Hu Jintao (2002-2012). Se observa en un texto de noviembre de 2005 titulado "Las prácticas y las ideas del servicio de las sociedades religiosas":

Desde tiempos antiguos, cada una de las religiones de nuestro país tiene la bondadosa tradición de ayudar en la aflicción, beneficiar a la gente y servir a la sociedad. Por ejemplo, el budismo propone "dignificar al país y dotar [a las personas] de sentimiento de alegría y beneficios"; el daoísmo plantea "con todos [ser] afectuosos, beneficiar al mundo de manera generosa y desinteresada"; el islam desea "hacer énfasis en los dos mundos, los dos mundos auspiciosos y prósperos"; el catolicismo y el protestantismo formulan que "siendo luz, siendo sal, glorificar al Señor y beneficiar a las personas", etcétera. Desde la llegada de la reforma y la apertura, cada una de las religiones de nuestro país desarrolla buenas tradiciones; de manera positiva despliegan una ayuda pública benevolente y logran que los sabios sean el foco de atención. En este proceso en el que continuamente se va profundizando la reforma y la apertura del país, las religiones, día a día, nutren sus capacidades, y en el servicio social se encuentran con nuevos desafíos y oportunidades. Sólo si en la idea de avanzar en el servicio social de las religiones se capta su significancia y preponderancia, se extienden la experiencia y el modelo exitoso con lecciones de experiencia local e internacional, y se crean de forma continua nuevos contenidos y formas de responsabilidad social, entonces se puede desarrollar la función de servicio social, y de esta manera las religiones y la sociedad socialista se pueden adaptar 
mutuamente, en un nivel más profundo, para guiar un territorio más extenso. ${ }^{23}$

Después de esta introducción, se alude a las palabras del vicepresidente Zhihui, de la organización filantrópica del Templo Nanputuo, de Xiamen:

El propósito de la práctica budista radica en llegar a convertirse en un buda; el propósito de llegar a convertirse en un buda es beneficiar a todos los seres vivos. De acuerdo con lo que se dice en el Sütra Huayan: "todos los seres vivos son las raíces de los árboles, todos los budas y bodhisattvas son el fruto esencial; por medio del agua de la gran misericordia se beneficia a todos los seres vivos, entonces pueden alcanzar las flores y los frutos de la sabiduría de los budas y los bodhisattvas. ¿Cómo puede ser esto?, si todos los bodhisattvas por medio del agua de la gran misericordia benefician a todos los seres vivos, entonces ésa es la causa de que puedan alcanzar la completa iluminación”. De esta manera, en el budismo Mahāyāna se anima vigorosamente a un "afecto abundante", "deseando el camino del bodhisattva de beneficiar a todos los seres vivos y convertirse en un buda, proponiéndose "dignificar al país y dotar la las personas] de sentimiento de alegría y beneficios", al mismo tiempo que se sirve en lo social, se beneficia a todos los seres vivos y se alcanza satisfactoriamente la iluminación como un buda. En otras palabras, beneficiar o dar mérito a los seres vivos es el propósito de la práctica del budismo, y además es la idea fundamental de la labor del servicio social. ${ }^{24}$

Es interesante la manera en que el lema se introduce en un contexto narrativo que, poco a poco, va creando las bases del discurso político-religioso actual. Incluso se atribuye una labor patriótica a figuras budistas como los bodhisattvas, quienes también deben dignificar al país. Ya en 1993, a propósito de las regulaciones en los monasterios, se vuelve a mencionar el lema en el Sexto Encuentro de Asociaciones Budistas:

El monasterio es el lugar ritual de estudio de los religiosos, del abad y del desarrollo del Dharma, es el lugar donde se conserva y desarrolla la cultura budista, es el centro de servicio de los religiosos, la base donde confieren beneficios a la sociedad, el lugar donde se establece el vínculo entre los discípulos budistas locales y los extranjeros. Los monasterios de-

${ }^{23}$ Oficina Nacional de Asuntos Religiosos, "Prácticas e ideas del servicio de la Asociación Budista de China” (服务的理念与实践 fúwù de lǐniàn yǔ shijiàn), 1 de noviembre de 2005.

${ }^{24}$ Idem. 
ben mantenerse solemnes y pacíficos, instituir los vientos del estudio y del camino puro, y desarrollar regularmente actividades de asuntos legales aplicándolos en todo tipo de áreas, para "dignificar al país y dotar [a las personas] de sentimiento de alegría y beneficios", así como para beneficiar a la civilización material socialista y construir una civilización espiritual. Las regulaciones pertinentes de la política, los códigos, las leyes y la Constitución de la República Popular China, así como la observancia de las reglas eclesiásticas budistas, establecen un medio definitivo para fortalecer la administración del templo, proteger los derechos y los intereses de los monasterios [y] garantizar la continuidad de las actividades budistas. ${ }^{25}$

Asimismo, el lema destaca en documentos que se refieren al papel del budismo en la educación y su relevancia en esta nueva era, como el texto titulado "El nuevo siglo de la educación budista”, del año 2010:

Sobre la integración de la educación budista, ‘acaso en esta nueva era [el budismo] no podría tomar seriamente la base situacional y el sistema educacional adoptando la reforma para consumar y mejorar el sistema educacional budista? ¿Acaso [el budismo] no podría mejorar la calidad de la educación desarrollando sus conocimientos, sus capacidades técnicas y la habilidad en las actividades, para impulsar en el futuro [y] en su administración educacional, de manera mutua, las prácticas sociales del budismo y la sociedad socialista, y que las personas talentosas realicen una contribución brillante para "dignificar al país y dotar [a las personas] de sentimiento de alegría y beneficios"? ¿Acaso [el budismo] no podría mejorar la calidad en general de la ética moral cultural en los colegios budistas, impartiendo el conocimiento y educando a las personas y desarrollando de manera exitosa la habilidad y la integridad de las personas talentosas? ¿Acaso el budismo no podría, en los diferentes niveles de colegios y universidades budistas, implementar la educación moral y reforzar el patriotismo y el colectivismo generalizando los ideales educacionales de la sociedad, respetando la disciplina, la ley y la educación ética social, impulsando a los religiosos en el camino ético y reforzando la construcción del budismo? ${ }^{26}$

\section{Los ejemplos señalados muestran cómo un lema es incor-} porado en diversos temas relacionados con las políticas del

${ }^{25}$ Oficina Nacional de Asuntos Religiosos, "El método para la administración de los monasterios budistas de la tradición han de toda China” (全国汉传佛教寺院 管理办法 Quánguǒ hànchuán fójiào sìyuàn guānľ̌ bànfã), 20 de diciembre de 2010.

${ }^{26}$ Oficina Nacional de Asuntos Religiosos, "La nueva era de la educación budista" (新世纪的佛教教育 Xìn shìjì de fójiào jiàoyù), 11 de noviembre de 2010. 
partido y que parten de una idea general para llegar a asuntos más específicos como la educación. De esta manera, las personas recuerdan el lema, que se repite una y otra vez, y lo relacionan con conceptos como patriotismo, moral, colectivismo, civilización, armonía y otros tantos propios de la narrativa política china.

A su vez, el lema se vincula a la literatura religiosa. El monje Shi Qingwen, de la Asociación Budista en Sanmen (provincia de Zhejiang), señala que las personas se emocionan al ver el lema "Dignificar al país y dotar [a las personas] de sentimiento de alegría y beneficios" en los monasterios. Este es el propósito del budismo, subraya el monje: "Hace dos mil años, Śākyamuni abandonó la vida de la realeza, siguió un camino de práctica y asumió la responsabilidad de liberar del sufrimiento a los seres humanos, lo que nos entrega el mayor ejemplo de servicio al país [bàoguó 报国]”. ${ }^{27}$ Luego, agrega que en la enseñanza budista hay un contenido vinculado al pensamiento patriótico: "gratitud y retribución por la transmisión de la bondad" es una de las frases más utilizadas por el budismo, y las cuatro bondades a las que debemos retribuir son: a los padres, a los seres humanos, al país y a las tres joyas (Buda, el Dharma, la enseñanza y la sangha o comunidad). Además, añade que entre las disciplinas monásticas se encuentran las siguientes reglas patrióticas a seguir: no traicionar al país, no difamar al gobernante del país y no evadir impuestos.

Sobre estas últimas afirmaciones de Shi Qingwen, me parece de especial interés la búsqueda y la reinterpretación de los valores confucianos y patrióticos en los sütras. Es evidente que se trata de textos apócrifos; la primera lista, sobre las retribuciones, alude al Dàchéng běnshēng xīndì guānjīng 大乘本生心地 观经, escritura mabāyāna que habla de la contemplación de la mente y corresponde a una de las tradiciones entre el periodo Wei del Norte (368-533) y la dinastía Tang (618-907), que tratan sobre la piedad filial confuciana. ${ }^{28} \mathrm{La}$ segunda lista, sobre las

${ }^{27}$ Shi Qingwen, "Diez claras buenas obras para el sentido positivo de un pueblo estable, una sociedad armónica y feliz” (浅淡十善业对人民安乐、社会和谐安定的 积极意 Qiăndan shishànyè duì rénmín ànlè, shèbuì héxié āndìng de jīji yì), Asociación Budista de Sanmen, enero de 2016.

${ }^{28} \mathrm{Yu}$, "Buddhism in Communist China", op. cit., p. 20. 
cuatro bondades, según mencionan algunos religiosos, alude a los cuatro preceptos que se mencionan en el Sütra Fanwang (梵 网经), pero no se señala cuáles son, por lo que suponemos que se trata de una reinterpretación con la que se pretende destacar el respeto a las autoridades que gobiernan el país.

\section{Discurso ecológico}

A este discurso patriótico se suma otro elemento que también colabora a la construcción de la narrativa político-religiosa, pero que se relaciona directamente con los problemas sociales y medioambientales que aquejan al país. Para entender la forma como el discurso patriótico se inserta en el discurso ecológico, es preciso referirse a lo que se entiende como budismo moderno, o "neobudismo", y su desarrollo en China.

La opinión general entre los budólogos es que, a principios de siglo Xx, el budismo se adaptó a la modernidad mediante un discurso que rechazaba los elementos mágicos y rituales y exponía tendencias universales e igualitarias. ${ }^{29}$ De acuerdo con Don Pittman, quien utiliza la caracterización que hace Gananath Obeyesekere sobre el budismo protestante en Sri Lanka, el budismo chino moderno incluye un mundo interior de ascetismo, racionalismo, rechazo a la innovación y en favor de la recuperación del mensaje original del Buda, del ecumenismo y de preferencia por las misiones globales. ${ }^{30}$ Por su parte, Heinz

${ }^{29}$ Se debe tener cautela al catalogar el budismo moderno como aquel que rechaza lo fantástico o mágico. El budismo, desde sus inicios, incorpora elementos sobrenaturales tanto en la doctrina como en las anécdotas, historias y literatura que se desarrolla. En la actualidad, los religiosos budistas chinos continúan utilizando estos elementos en las explicaciones que entregan a los devotos laicos, quienes también añaden elementos fantásticos o milagrosos a sus propias experiencias religiosas. Por eso es importante tener en cuenta que el moderno rechazo a los elementos mágicos queda en el discurso y no en la práctica. Véase María Elvira Ríos, "Bodhisattva Guanyin: un estudio sobre cómo conciben las devotas su encuentro con la imagen de Guanyin”, en Romer Cornejo (coord.), China: estudios y ensayos en honor a Flora Botton Beja, México, El Colegio de México, 2012, pp. 335-378.

${ }_{30}$ Tarocco, The Cultural Practices..., op. cit., pp. 11-12. Richard Gombrich y Gananath Obeyeskere enfatizan la influencia del cristianismo en las formas modernas del budismo sinhales (Sri Lanka) en los siglos XIX y Xx. Ellos utilizan el término "budismo protestante" para sugerir que ese budismo modernizado protesta en contra de la colonización europea y las misiones cristianas, adoptando elementos del protes- 
Bechert lo describe como un movimiento que se extiende a distintas áreas geográficas y escuelas, y lo reinterpreta como un "camino racional de pensamiento" que hace hincapié en la razón, la meditación y el redescubrimiento de los textos canónicos. ${ }^{31}$ MacMahan agrega que el budismo moderno reduce la importancia del rito, la adoración de las imágenes, las creencias y las prácticas "folclóricas", y se une a las reformas sociales y los movimientos nacionalistas. ${ }^{32} \mathrm{~A}$ estas características se añaden los señalamientos de Charles Taylor sobre el expresionismo romántico de los movimientos literarios, artísticos y filosóficos que surgieron como una crítica al racionalismo y que pretenden reafirmar la sacralidad y el misterio buscándolos en la naturaleza, el arte y el espíritu humano. Ve la naturaleza y el sentimiento como fuentes de moralidad y conocimiento espiritual. Con base en estas expresiones de Taylor, MacMahan sugiere que el budismo moderno le debe al Romanticismo (lo sentimental sobre lo racional) muchas de sus tendencias, como el retorno a la naturaleza y a la interconexión con los seres vivos. A su vez, agrega que la modernidad trae consigo una nostalgia de lo premoderno y la esperanza de que las tradiciones antiguas ayuden al reencantamiento del mundo por medio, irónicamente, de su propio tipo de "ciencias" y "tecnologías". ${ }^{33}$

Ahora bien, para explicar cómo se podrían manifestar las ideas que MacMahan recoge y analiza del budismo moderno en los discursos del budismo chino, recupero el contenido de una parte del discurso del monje Shi Qingwen a propósito del consumo de carne y el llamado al vegetarianismo. El maestro se detiene en una de las reglas monásticas que todo budista (religioso o laico) debe seguir: no matar a los seres vivos, y se refiere a ella en los siguientes términos:

tantismo. Bajo esta influencia, Gombrich y Obeyeskere señalan que la religión se privatiza y se internaliza; el significado verdadero no es aquello que tiene lugar en una celebración pública o en un ritual, sino lo que pasa en la mente o el alma. Véase Richard Gombrich, Theravada Buddhism: A Social History from Ancient Benares to Modern Colombo, Londres, Routledge, 1988, p. 216.

${ }^{31}$ David. L. MacMahan, The Making of Buddhist Modernism, Nueva York, Oxford University Press, 2008, p. 7.

${ }^{32}$ Ibid., p. 11.

${ }^{33}$ Charles Taylor, Sources of the Self: The Making of Modern Identity (1989), citado en ibid., p. 12. 
Se cree que alimentándonos de la sangre y la carne de los animales podemos nutrir nuestro cuerpo, pero, en realidad, según las condiciones en las que hoy en día se procesa la carne, no es saludable, pues ésta tiene acumulada una serie de fertilizantes, pesticidas, hormonas, antibióticos e incluso medicina anticonceptiva que no sólo no beneficia a la salud, sino que produce enfermedades como el síndrome respiratorio agudo severo o la influenza. Este tipo de enfermedades infecciosas tiene que ver con la alimentación con carne. Los expertos señalan que las personas vegetarianas son más longevas que los carnívoros, y que los vegetarianos raramente acuden a los hospitales. ${ }^{34}$

Otro elemento que señala el monje es el relativo a los gases que emiten las vacas, que se explican por su dieta alimenticia. Todas las vacas producen entre $800 \mathrm{ml}$ y un litro de metano diario, químico que colabora al calentamiento global. Esto es resultado de que el hombre ha requerido de la vaca para alimentarse de su leche y su carne, para usar su cuero, para producir jabón y para otras cosas más, por lo que altera su dieta. ${ }^{35}$

Me parece interesante la adaptación del discurso budista a un lenguaje que considera los problemas actuales de los alimentos de procedencia animal, cuyo procesamiento incorpora sustancias tóxicas para el cuerpo humano que causan enfermedades o problemas de salud. Como corrobora MacMahan, el budismo remoderniza el Dharma como un camino para volver a encantar, mostrando un escape a la reencarnación que, al mismo tiempo, se mantiene dentro de una estructura cosmológica naturalista y alineada con las sensibilidades racionalistas y científicas. ${ }^{36}$

Según los informes y las imágenes publicadas por la asociación, otro lema decora los muros de los templos y está acorde con los problemas ambientales y ecológicos que sufre el país. El lema es "Wénmíng jìngxiāng, héli fangshēng, jiànshè shēngtài siyuàn” 文明敬香、合理放生、建设生态寺院, ${ }^{37} \mathrm{y}$ se refiere al cuidado que deben tener los devotos laicos y religiosos con el

${ }^{34}$ Shi, Qiăndan shíshànyè..., op. cit.

${ }^{35} \mathrm{Idem}$.

${ }^{36}$ MacMahan, The Making of Buddhist Modernism, op. cit., p. 13.

${ }^{37}$ Asociación Budista de China, "Encender inciensos de manera civilizada, liberar a los animales de forma razonable, construir monasterios ecológicos” (文明敬 香、合理放生、建设生态寺院 宣传海报发布仪式在京举行 Wénming jingxiāng, bélǐ fangshēng, jiànshè shēngtài sìyuàn xuächuán băibào fäbù yíshì zài jìng jưxing), 1 de enero de 2016. 
medio ambiente del templo: encender inciensos de forma civilizada y no exagerada; liberar animales con un guía y de manera razonable para no producir desórdenes ecológicos por elegir lugares inadecuados a su hábitat; proteger el medio ambiente de los templos y procurar que éstos se edifiquen de forma ordenada, es decir, con el control que tiene el gobierno sobre la construcción.

Sumado a estos lemas, y vinculado a la protección del medio ambiente, en la página de la Asociación se lee: "sijué dǐzbi shāo gāoxiāng, shāo dàxiāng de bù wénmíng xiànxiàng” 自觉抵制烧 高香、烧大香的不文明现象, ${ }^{38}$ resistirse conscientemente a encender inciensos grandes, pues encender inciensos grandes es un fenómeno no civilizado. El abad del monasterio Guangji-si en Beijing, el maestro Yanjue, explica al respecto:

De esta manera, los monasterios deben encender inciensos de forma civi-
lizada, realizar la liberación de animales de manera razonable y construir
templos de manera ecológica y civilizada. Los inciensos gruesos, grandes y
de mala calidad traen mucha contaminación a los monasterios y son de
gran peligrosidad para la seguridad de las personas y la edificación del mo-
nasterio. [El maestro Yanjue] espera extender a todos la práctica de ofre-
cer inciensos de manera civilizada, sobre todo que no exceda las tres
varillas de inciensos, y que además utilicen inciensos de buena calidad,
cortos y delgados, y que se opongan a encender inciensos grandes,
gruesos y de mala calidad. El maestro Yanjue especialmente enfatiza
que ofrecer incienso de manera civilizada refleja el nivel de administra-
ción del monasterio. Un monasterio civilizado y ecológico incluye un
ambiente bello y una construcción con salones limpios, con esculturas
dignas, etcétera. El monasterio no es un lugar especializado en encen-
der inciensos, sino que es el lugar en el que los religiosos realizan sus
prácticas religiosas, es la casa espiritual de los devotos, es un lugar de
intercambio cultural; ir al monasterio para encender inciensos es una
lectura errónea de [la función] de los monasterios. ${ }^{39}$

Otra manera de entender este discurso ecológico es la que recoge el estilo "romántico" señalado por Taylor, que podemos

${ }^{38}$ Idem.

${ }^{39}$ Asociación Budista de China, "La oficina de la Asociación Budista de China en Beijing implementa el trabajo de llevar a cabo de manera gratuita el ofrecimiento de inciensos de manera civilizada” (中国佛教协会在京直属寺院实施免费赠香推进 文明敬香工作 Zhōngguó Fójiào xiébuì zài jīng zhíshǔ sìyuàn shíshǐ miănfêi zèng xiāng tuīìn wénmíng jìngxiāng gōngzuò), Oficina Nacional de Asuntos Religiosos, 15 de abril de 2016. 
observar en la ponencia del maestro Shuguang en la Conferencia internacional sobre civilización ecológica e informes ambientales (junio de 2015), que organizaron el Centro Yale de Beijing, la Universidad de Comunicaciones de China, el Centro Pulitzer y el Colegio de Estudios de Medio Ambiente y Silvicultura de Yale. El maestro Shuguang se refiere al Sutta Brabmajala y dice: "Toda la tierra y el agua son mis predecesores, todo el fuego y el viento son mi cuerpo". El maestro agrega que cada célula en el cuerpo humano es un metabolismo, y todo lo que desecha nuestro cuerpo nutre el pasto, los árboles y las plantas en el suelo. Señala que es muy difícil intentar ver un límite entre la naturaleza y uno mismo: "La manera como vivimos define el medio ambiente en que vivimos, esto es un precepto budista muy importante [...] Proteger el ambiente en que vivimos es amar nuestro cuerpo". ${ }^{40}$ Más adelante argumenta que el budismo siempre ha insistido en la protección del ambiente. La prueba más evidente es que muchos templos antiguos se encuentran en famosas montañas donde hay un entorno bien cuidado. Fueron los monjes quienes plantaron los bosques que hoy se observan en el famoso monte Emei, en la provincia de Sichuan. La plantación de los árboles se inició durante la dinastía Tang y, hoy por hoy, es una práctica que mantienen y cultivan los monjes. ${ }^{41}$

\section{Budismo humanista}

Después de revisar dos de los tres elementos que construyen el discurso político-religioso del budismo en China, me referiré al tercero, el concepto de rénjiān fójiào 人间佛教, el budismo humanista del maestro taiwanés Shi Xingyun 释星云, quien funda la corriente Foguangshan en Taiwan. Stuart Chandler argumenta que el maestro Xingyun respeta las prácticas budistas secularizadas, entrega una interpretación del Dharma que se ajusta más a este mundo y rompe los límites entre el monaste-

\footnotetext{
${ }^{40}$ Shi Shuguang, "Cultural and Religious Perspective", Ecological Civilization, Beijing, Pulitzer Center, 2015, pp. 39-40.

${ }^{41}$ Idem., pp. 40-41.
} 
rio y la sociedad en general. ${ }^{42} \mathrm{La}$ Asociación Budista de China también subraya el sentido "humanitario" e incluye el término rénjiān en la lista de conceptos que utiliza en sus pláticas y aplica parte del discurso del maestro Xingyun de adecuación del mundo religioso a la vida moderna. En el desarrollo de las prácticas religiosas, así como en la construcción del discurso religioso, la asociación se interesa en las acciones del budismo humanista de Taiwan, las analiza y observa para tomar aquellas ideas que no interfieran en la narrativa político-religiosa. Al respecto, es interesante la intención de crear unidad con Taiwan desde la consideración y la influencia de la doctrina del budismo humanitario. Para esto, recurren al lema Liăng àn Sān di 两岸三 地: Dos costas y tres tierras, frase que se refiere a las orillas de Taiwan y el continente, junto con las tierras de Macao y Hong Kong, es decir, a la unidad territorial, y agrego: a la unidad de líderes religiosos. La Asociación Budista de China mantiene contacto con los miembros de Foguangshan, y en mayo de 2015 recibió a 22 representantes, laicos y religiosos. En esa ocasión, el presidente de la asociación, el maestro Xuecheng, señaló que el budismo de "ambas costas" es un solo cuerpo que cada día se va desarrollando, y sus religiosos insisten en la necesidad de reflexión mutua y de cómo trabajar en las labores del budismo. ${ }^{43} \mathrm{~A}$ su vez, Chexing, el vicepresidente de la Asociación Budista en Shaanxi, se refiere al budismo humanista y destaca la labor del mencionado Zhao Pulao. Chexing señala que fue el laico Zhao quien, después de las reformas de Taixu, hizo hincapié en la misión "humanitaria” del budismo en China. Además, y a propósito de los lemas señalados anteriormente, Chexing agrega que con un budismo humanitario se conseguirá "dignificar al país y dotar [a las personas] de un sentimiento de alegría y beneficios". ${ }^{44}$

${ }^{42}$ Chandler, Establishing a Pure Land on Earth, op. cit., p. 5. El discípulo de Taixu, el maestro Yinshun 印顺 (1905-2005), es quien usa el término rénjiān, pues consideraba que servía para determinar que los budistas debían participar activamente en la sociedad humana. Shi Xingyun rescata el término rénjiän y eleva la figura humana del Buda Śakyamuni y su actuar en el mundo.

${ }^{43}$ Asociación Budista de China, "Visita de la delegación China Taiwan del Budismo Humanista” (台湾中华人间佛教联合总会一行来访 Táiwān zhōnghuá rénjiān fójiào liánhé zǒnghuì yīháng láifãng), mayo de 2015.

${ }^{44}$ Chexing, “Budismo humanista y bien público benevolente" (人间佛教与公 益慈善 Rénjiān fójiào yŭ gōngyì císhàn), octubre de 2014. 
El monje y profesor asociado del Departamento de Filosofía de la Universidad de Qinghua, Shengkai, señala que el budismo en China tiene tres grandes realidades: un sistema socialista bajo el liderazgo del Partido Comunista, una economía de productos y una época de encuentro de civilizaciones del este y del oeste. Shengkai, al preguntarse cómo puede el budismo mantener su carácter central, su pureza y su desarrollo tradicional, señala que lo fundamental es que comprenda y ponga en práctica la base contemporánea del actual budismo humanista. ${ }^{45}$

\section{Conclusiones}

Los antecedentes históricos del discurso político-religioso en la China del siglo xx permitieron comprender la constante reinterpretación y actualización de ese discurso narrativo. Asimismo, y considerando las reflexiones de MacMahan, se confirma que, en todas las áreas geográficas donde las tradiciones budistas han surgido, el Dharma se ha entendido en términos de categorías, prácticas, convenciones y circunstancias históricas de personas particulares en un tiempo específico. Así, la doctrina ha sido adaptada mediante la transformación, la absorción, la suplantación y el acomodo de las ideas y las prácticas locales. ${ }^{46}$ En esta recopilación de discursos de la Asociación Budista de China se han analizado las adaptaciones del budismo chino en el mundo contemporáneo y se ha reflexionado sobre los elementos que intervienen en la creación de nuevas narrativas en relación con las responsabilidades de los religiosos y los devotos laicos hacia el país y su gobierno. Al respecto, destaca el lema " $A \hat{A} i$ guó ài jiāo", amor a la patria y a la doctrina, consigna fundacional de esta narrativa que se repite en innumerables anuncios difundidos en calles y sectores públicos de las ciudades chinas. Esta frase per se es un emblema, porque los mismos caracteres

${ }^{45}$ Asociación Budista de China, "Shengkai: Tres grandes dimensiones del budismo humanista: el espíritu del Buda, la tradición budista china, el budismo contemporáneo (圣 凯: 人间佛教的三大维度一佛陀精神、中国佛教传统、现当代佛教 Shèngkăi: rénjiān fójiào de sān dà wéidù - Fótuó jīngshén, Zhōngguó fójiào chuántǒng xiàn dāngdài fójiào), 8 de julio de 2016.

${ }^{46}$ MacMahan, The Making of Buddhist Modernism..., op. cit., pp. 18-19. 
también funcionan como símbolos de su propio significado. Además, su constante presencia en los espacios públicos del país y en los discursos la convierte en emblema nacional. De la misma manera, se sugiere que no sólo " Ài guó ài jiäo" representa el patriotismo y las prácticas religiosas que ayudan a mejorar las condiciones sociales del país, sino que también la palabra guó, país, es equivalente a partido, lo que nos lleva a suponer que en el sentimiento patriótico subyace el amor al partido.

Del lema "Ài guó ái jiāo" se desprenden otras consignas que se insertan en los discursos y los espacios religiosos como sellos que identifican las prácticas que el gobierno espera que la Asociación Budista difunda entre los fieles. En la incorporación de estos lemas se sigue reinterpretando, al igual que en el pasado, la literatura budista, como una manera de fundamentar las nuevas prácticas o las regulaciones impuestas por el gobierno. En este proceso de reinterpretación se recurre a elementos neobudistas que apuntan al bienestar de la sociedad, a las mejoras del medio ambiente y a la protección de los animales, entre otros. Finalmente, se agrega el papel del budismo humanista taiwanés, que desde una mirada global y modernizadora colabora a la construcción de la narrativa religiosa de la Asociación Budista, como también al acercamiento entre Taiwan y el Partido Comunista Chino. Estas características, que aluden a procesos históricos del gobierno chino y del budismo, a la inclusión de las transformaciones del budismo en el exterior y a su influencia en el mundo moderno, así como a la búsqueda de mayor relación con el pueblo taiwanés, hongkonés y chino en el extranjero, conforman una estrategia narrativa que se extiende a las diversas sedes de la Asociación Budista en la nación china, y manifiestan no sólo la adecuación religiosa al mundo político, sino también los cambios en la comprensión de la doctrina budista china y, por lo tanto, en la finalidad sociorreligiosa del devoto chino. En este proceso de transformación doctrinaria, habrá que seguir analizando y reflexionando sobre la repercusión de la estrategia de la narrativa político-religiosa.

Dirección institucional de la autora:

Centro de Relaciones Internacionales

Facultad de Gobierno, Universidad del Desarrollo 
Av. Plaza 680, Las Condes,

Santiago, Chile

\section{Bibliografía}

Asociación Budista de China, "Breve introducción a la Asociación Budista de China” (中国佛教协会简介 Zhōngguó Fójiào xiébuì jiăn jiè), abril de 2012. [<www.chinabuddhism.com.cn/js/jj/201204-20/869.html $>$, consultado entre noviembre-diciembre de 2015, y enero-febrero de 2016.]

Asociación Budista de China, "Encender inciensos de manera civilizada, liberar a los animales de forma razonable, construir monasterios ecológicos” (文明敬香、合理放生、建设生态寺 院 宣传海报发布仪式在京举行 Wénming jingxiāng, héli fangshēng, jiànshè shēngtài sìyuàn xuāchuán hăibào fäbù yishì zài jīng jǔxing), 1 de enero de 2016. [ < http://www.chinabuddhism.com. $\mathrm{cn} / \mathrm{xw} / \mathrm{yw} 1 / 2016-01-26 / 10263 . \mathrm{html}>$, consultado en febrero de 2016.]

Asociación Budista de China, "La oficina de la Asociación Budista de China en Beijing implementa el trabajo de llevar a cabo de manera gratuita el ofrecimiento de inciensos de manera civiliza$\mathrm{da}$ ” (中国佛教协会在京直属寺院实施免费赠香推进文明敬香 工作 Zhōngguó Fójiào xiébuì zài jīng zhishǔ sìuàn shisȟ̌ miănfei zèng xiāng tuijjin wénming jìngxiāng gōngzuò), Oficina Nacional de Asuntos Religiosos, 15 de abril de 2016. [< http://www. sara.gov.cn/ttdt/333480.htm >, consultado en junio de 2016.]

Asociación Budista de China, "Shengkai: Tres grandes dimensiones del budismo humanista: el espíritu del Buda, la tradición budista china, el budismo contemporáneo” (圣 凯: 人间佛教的三 大维度一佛陀精神、中国佛教传统、现当代佛教 Shèngkăi: rénjiān fójiào de sān dà wéidù - Fótuó jīngshén, Zhōngguǒ fójiào chuántöng xiàn dāngdài fójiào), 8 de julio de 2016. [< http:// www.chinabuddhism.com.cn/special/jlkjc/yxyt061/2016-0708/10958.html >, consultado en julio de 2016.]

Asociación Budista de China, "Unámonos, contribuyamos al desarrollo de la buena tradición budista para dignificar al país y dotar [a las personas] de alegría y beneficios” (团结起来, 发 扬佛教优良传统为庄严国土利乐有情作贡献一在中国佛教 协会第五届全国 Tuánjié qǔlai fayáng fójiào yōuliáng chuántǒng wèi zhuāngyán guótǔ lilè yǒuqíng zuò gòngxiàn - zài Zhōngguó Fójiào xiébui dì wǔ jiì quánguǒ), 23 de febrero de 1987. [ < http:// 
www.chinabuddhism.com.cn/js/hb/2012-03-15/467.html >, consultado en junio de 2016.]

Asociación Budista de China, "Visita de la delegación China Taiwan del budismo humanista” (台湾中华人间佛教联合总会一行来 访 Táiwān zhōnghuá rénjiān fójiào liánhé zǒnghui yīháng láifäng), mayo de 2015. [ <www.chinabuddhism.com.cn/xw/jliu/201505-19/8964.html > , consultado en febrero de 2016.]

Chandler, Stuart, Establishing a Pure Land on Earth. The Foguang Buddhist Perspective on Modernization and Globalization, Honolulu, University of Hawai'i Press, 2004.

CheXING, "Budismo humanista y bien público benevolente" (人间 佛教与公益慈善 Rénjiān fójiào yŭ gōngyì císhàn), octubre de 2014. [<www.chinabuddhism.com.cn/WFB27th/zt/2014-1017/7128.html >, consultado en febrero de 2016.]

Gombrich, Richard, Theravada Buddhism: A Social History from Ancient Benares to Modern Colombo, Londres, Routledge, 1988.

MacMahan, David L., The Making of Buddhist Modernism, Nueva York, Oxford University Press. 2008.

Miskimmon, Alister, Ben O'Loughlin y Laura Roselle, Strategic Narratives: Communication Power and the New World Order, Nueva York, Routledge, 2013.

Oficina Nacional de Asuntos Religiosos, "Cambio y desarrollo histórico” (历史沿革 Lishb̌ yánggê), 27 de mayo de 2015. [ < http:// www.sara.gov.cn/jqgk/lsyg/index.htm $>$, consultado en junio de 2016.]

Oficina Nacional de Asuntos Religiosos, "El método para la administración de los monasterios budistas de la tradición han de toda China” (全国汉传佛教寺院管理办法 Quánguǒ bànchuán fójiào sìyuàn guānlı̌ bànfä), 20 de diciembre de 2010. [<http://www. sara.gov.cn//xxgk/zcfg/qgxzjttxgjgzd/6517.htm >, consultado en junio de 2016.]

Oficina Nacional de Asuntos Religiosos, "La nueva era de la educación budista” (新世纪的佛教教育 Xinn shiji de fójiào jiàoyù), 11 de noviembre + de 2010. [< http://www.sara.gov.cn//zjzc/ zjjy/4925.htm $>$, consultado en marzo de 2017.]

Oficina Nacional de Asuntos Religiosos, "Prácticas e ideas del servicio de la Asociación Budista de China” (服务的理念与实践 fúrwù de lǐniàn yŭ shijiàn), 1 de noviembre de 2005. [ < http://www.sara. gov.cn//1lyj/4179.htm $>$, consultado en junio de 2016.]

Ríos, María Elvira, "Bodhisattva Guanyin: un estudio sobre cómo conciben las devotas su encuentro con la imagen de Guanyin", en Romer Cornejo (coord.), China: estudios y ensayos en 
honor a Flora Botton Beja, México, El Colegio de México, 2012, pp. 335-378.

SHI QINGWEN, "Diez claras buenas obras para el sentido positivo de un pueblo estable, una sociedad armónica y feliz" (浅淡十 善业对人民安乐、社会和谐安定的积极意 Qiăndan shishànyè duì rénmín ānlè, shèbui béxié ānding de jījí yì), Asociación Budista de Sanmen, enero de 2016. [<www.baohuasi.org/ gnews $/ 2016128 / 2016128337258 . h t m l>$, consultado en febrero de 2016.]

Shi Shuguang, "Cultural and Religious Perspective", Ecological Civilization, Beijing, Pulitzer Center, 2015, pp. 39-43.

STARK, Rodney y Eric Y. Liu, “The Religious Awakening in China”, Review of Religious Research, vol. 52, núm. 3, marzo de 2011, pp. 282-289. [ < www.jstor.org/stable/23055552>, consultado el 22 de octubre de 2015.]

TARocco, Francesca, The Cultural Practices of Modern Chinese Buddhism. Attuning the Dharma, Nueva York, Routledge, 2007.

Welch, Holmes, The Practices of Chinese Buddhism 1900-1950, Cambridge, Harvard University Press, 1967.

Yu, David C., "Buddhism in Communist China: Demise or CoExistence?", Journal of the American Academy of Religion, vol. 39, núm. 1, marzo de 1971, pp. 48-61. [<www.jstor.org/ stable/1461680>, consultado el 22 de octubre de 2015.]

ZHANG QI, "Las múltiples contribuciones del devoto laico Zhao Puchu en las decisiones sobre la política, leyes, teoría y práctica de las religiones en nuestro país en este nuevo periodo" (赵朴 初居士对新时期我国宗教政策、法律、理论、实践方面做 出的诸多贡献, Zháo Pǔzhū jūshì duì xīn shíqi wǒguó zōngïào zhèngcè, fâlù, lìlùn, shijiàn fängmiàn zuòchü de zhūduō gòngxiàn), Fojiao Yanjiu 佛学研究, vol. 1, 2014, pp. 390-403. [<www.cqvip. com/QK/87498X/201401/664804404.html >, consultado en febrero de 2016.] 